DOI 10.14746/ps.2015.1.29

\title{
National Visions of EU Defence Policy - common denominators and misunderstandings, eds. Federico Santopinto, Megan Pri- ce, Centre for European Policy Studies, 2013, pp. 176.
}

It seems that the European Security Strategy of 2003 so far described as an example of progress towards European integration is losing more and more on its significance. It is common in the world of politics, even saying that the strategy of the term has lost its usefulness. Others even claim that it lacked key elements from the beginning, being a mere compromise to satisfy European politicians without its credibility and a clear and deliberate policy. But as it happens, in fact, believes scientists are divided and not all of them yet are so critical to bring the project. It is worth to mentioning that more balanced observers recognize the significant contribution to the strategy consolidate the European project. But even more benignant reviews European Security Strategy are offered in a general context tribute to the division, if not a praise.

Previous disappointment sparked renewed discussion on how to define again the collective EU Strategy in the field of defense and security. Taking into account recent developments on European policy based on the Treaty of Lisbon, one can conclude that due to its ineffectual, it is necessary to reconsider the EU tools and related expectations. In addition, conflicts in Libya, Mali and Syria helped to draw conclusions and create a not favorable opinion of Europe military capabilities to respond to emergencies in real-time.

The tenth anniversary of the functioning of the European Security Strategy has forced a broad range of political reflection on the resumption of the debate on the future vision of the EU Security Strategy and the Common Security and Defence Policy as the main governing body. The proceedings took place in December 2013 by the European Council where Poland was one of the leading European countries. For the first time since the entry into force of the Treaty of Lisbon, the European Council held thematic debate on defense. Identified priority actions for closer cooperation. In the opinion of the individual writers of this collective work previous attempts to have a common European strategy on the assumption contained many inaccuracies and provoked many questions that were not answer. The presumption of common interests that may occur at this level Brussels to awake in each state capitals did not work out. Although well intended, it was too optimistic approach that invented collective interests, instead of deriving them from the real driving force of the EU member states. This elaboration therefore aims to reverse the usual exploration approach applied. Instead of an investigation from the point of view common European interests guided CSDP research studies, each Member State will consider the CSDP as a mechanism to serve individual particular interest.

On the basis of this study we can accept the statement that each State to identify as a member of the EU security strategy must at the beginning understand and know what are the expectations from CSDP. Over the last few years the functioning of the ESS, we can observe a discrepancy between perception and performance of defense policy in Europe. This book narrows the multipolarity and gives this phenomenon more pronounced shape. Based on description of individual authors, we can conclude lack of decisiveness and straight vision for the future of the individual member states towards the CSDP. In addition, it is difficult to define what principle the Member States anticipate or demand from the CSDP, 
and what kind of role European defense policy should play in their national strategies. Therefore, in this book we can see a lot of complex questions, but unfortunately the majority without answers and concrete guidance on issues concerning the future of the CSDP. Nevertheless, this is a very productive discussion, which can be the foundation of the common EU strategy.

For a deeper analysis of the above questions, a few scientists were sent to seven research centers of EU Member States. They had the opportunity to explore the world of foreign policy of Paris, London, Berlin, Rome, Warsaw, Stockholm and Madrid looking for CSDP through the prism of each state. Anatomy of the book looks like a tour of Europe, examining individual approach individual members of international organizations and the acceptable level of strategic autonomy of the country. The authors describe their observations on the national culture, as a set of standards, religions, beliefs and principles of the use of hard power in the eyes of decision makers. Reading the development of each author, it seems that everyone is defending their country describing their undeniable contribution to the ESDP, nevertheless it is apparent the lack of concrete solutions and visions in order to remedy this situation. It looks like that nobody wants to take the so-called "bull by the horns" and preside over the reorganization and the creation of a new ESS.

The diversity of interpretations, perceptions and opinions of individual members were gathered in the summary section, which aims to show both similarities and differences, and errors of national security strategy. Therefore, studies have focused on the accurate identification of joint surfaces agreement and areas where opinions are divided or we can see a total lack of approach to the CSDP. Such reasoning is essential for the European perception of peacekeeping operations, which can be considered in two areas. The first one is to serve as a basis for the continuation and implementation of policy instruments checked by the CSDP. The second is intended to demonstrate gaps and differences of opinion for the CSDP, and by finding common denominators of this agreement to make more efficient EU policies. The biggest dissonance we can observe among the strategic cultures. For a special attention deserves a big difference of opinion between France and Germany about the essence of the functioning of the CSDP. Manuel Muniz as a lawyer and PhD student in International Relations at Oxford described France as not only a strong military ally, but the state with the most advanced security program and defense policy that allows to solve the crises well beyond the borders of Europe. Christian Wurzer - a PhD student at Vienna University claims that quite different beliefs has Germany, who argue that the CSDP is mainly an instrument of European integration. Based on their historical experience, which significantly influence the consciousness of the nation, they are the last country who will vote for the use of force. Therefore, Germany's most deeply appreciate the power of diplomacy, which should be mainly use during settlement of conflicts.

The main motto of these considerations is to clarify what actually CSDP is, for each Member State, prior to the start of serious discussions on the shape and the vision of a united European security strategy. However, they require a mature level of strategic thinking, which is unfortunately invisible by some EU members. This problem appears most clearly in the chapter describing Spain by Federico Santopinto - Head of Research at GRIP (fr. Groupe de recherche etd'information sur la paix et la sécurité) in Brussels, where we can noticed a lack of clarity or strategic guidance. One can say that Spanish policy towards CSDP displays both loyalty and confusion, in an attitude that is both honorable and extremely risky. However, each country has its distempers. Italy, for example, described by 
F. Santopinto, seems to stand at the crossroads balancing its commitment to NATO and the CSDP. However, with so many challenges on strengthening European security and continuous hope that this protection is and will be provided by NATO, is not convinced of fully devotion for the CSDP. France seems to be disappointed helplessness so far CSDP, her little commitment and a lack of decisiveness force them to take the heading more towards NATO and its own self-defense. Authorities reserve the right to make decisions regarding the use of force outside the country where it could have an impact on the national security or find this necessary. Reading the chapter about Poland written by Joanna Dobrowolska-Polak - researcher at the Institute for Western Affairs, Poznań, one can see how much has changed our attitude towards an integrated Europe for the last few years. Polish increasingly expressed their views on the international arena of the need for reforms to improve the efficiency of the CSDP actions taking a leading part in conferences on European Security. In the chapter on Sweden described by Alessandro Marrone - researcher at Instituto Affari Internazionali (IAI) in Rome, we can learn about the active involvement of this state in favor of European security. They see the need to not only necessary to maintain the stabilization of the security of the Baltic States but, but also the countries directly bordering Russia for its own security by observing lately worrying and expansionary policy of the Russian Federation.

In the part about The United Kingdom's written by Giovanni Faleg - Associate Research Fellow at the EU Foreign Policy Unit of the Centre for European Policy Studies (CEPS) in Brussels we can find out that participation in the EU's Common Security and Defense Policy (CSDP) is at a crossroads. Yet, as this research shows, the UK's stance towards European defense has never had so many doubts. Due to the budget cuts which an impact on public defense spending, the Coalition Government has privileged bilateral cooperation with France as a defense agreement which affect negatively multilateral initiatives within the EU framework. It looks like that this new political doctrine, combined with a prolonged sense of frustration towards Brussels-based, ineffective crisis management structures, has caused Britain to deviate from the course of CSDP.

Based on this study EU members do not treat themselves seriously in matters of security and defense, however. Even if you change their mind and will succeed in filling the gaps on strategic cultural differences, this still sustained trend in defense budget cuts in European countries will not allow to equip armies with the means that would allow for longer survival on the battlefield without the support of NATO. The European Union has not once proved the effectiveness of the force of diplomacy, but in these times where the environment is becoming increasingly complex and unfriendly soft power must go hand in hand with hard power.

Collective work of National visions of EU defense policy consists of seven main chapters describing the visions of EU defense by France, Germany, Italy, Poland, Spain, Sweden and the United Kingdom. In addition it is a specific link between the theoretical considerations about the concept of the European Security Strategy and contemporary international issues which have a direct impact on CSDP. At the same time it stress how much is needed a dialogue between Member States in order to improve European defense. The advantage of this book is very readable narrative form of individual authors, which is not a problem even for people who have not dealt with this issue before. The results of research in the various countries are valuable compendium of information both for students of political science and international relations. Deserves to be called the highlight selection and use of appropriate 
sources of knowledge of the issues presented. In recognition of the merits the use of so many authors from different countries in order to present a broader picture of the CSDP, which undoubtedly contributed to raising the cognitive asset. However, the drawback of these studies, especially for readers interested in the subject, is too great detail devoted the various national strategies and their brevity in the description. However, this is the result of chosen form of work that has to be primarily an impulse to further explore the issues and dialogue between Member States. Summing up National visions of EU Defence Policy is a valuable development, containing a number of innovative touches the individual authors and provides added value in all considerations of metamorphosing vision of CSDP in the last decade.

Paweł MARCINKOWSKI

Poznań 